COE-RES Discussion Paper Series

Center of Excellence Project

The Normative Evaluation and Social Choice of

Contemporary Economic Systems

Graduate School of Economics and Institute of Economic Research Hitotsubashi University

COE/RES Discussion Paper Series, No.165

April 2006

Tariff Revenue Competition in a Free Trade Area:

The Case of Asymmetric Large Countries

Taiji Furusawa

(Hitotsubashi University)

Naoto Jinji

(Okayama University)

Naka 2-1, Kunitachi, Tokyo 186-8603, Japan

Phone: +81-42-580-9076 Fax: +81-42-580-9102

URL: http://www.econ.hit-u.ac.jp/ coe-res/index.htm

E-mail: coe-res@econ.hit-u.ac.jp 


\title{
Tariff Revenue Competition in a Free Trade Area: The Case of Asymmetric Large Countries
}

\author{
Taiji Furusawa* $\quad$ Naoto Jinji ${ }^{\dagger}$
}

April 13, 2006

\begin{abstract}
Richardson (1995) shows the striking result that tariff revenue competition between two symmetric member countries of a free trade area (FTA) results in complete elimination of external tariffs if there exists a pure-strategy Nash equilibrium at all. He also conjectures without building a model that if member countries are asymmetric in the market size, there exists a pure-strategy Nash equilibrium in which both countries set positive external tariffs. We explicitly extend his tariff competition model into the case of asymmetric FTA member countries, and confirm his conjecture. We also characterize a mixed-strategy Nash equilibrium in the case of symmetric countries.
\end{abstract}

Keywords: tariff revenue competition; free trade area; external tariff rate. JEL classification: F15.

\footnotetext{
*Graduate School of Economics, Hitotsubashi University, 2-1 Naka, Kunitachi, Tokyo 186-8601, Japan. Phone \& Fax: +81-42-580-8866. E-mail: furusawa@econ.hit-u.ac.jp

${ }^{\dagger}$ Faculty of Economics, Okayama University, 3-1-1 Tsushima-Naka, Okayama 700-8530, Japan. Phone \& Fax: +81-86-251-7525. E-mail: jinji@e.okayama-u.ac.jp
} 


\section{Introduction}

Preferential Trade Agreements (PTAs) are prevalent all over the world. According to the World Trade Organization (WTO), it is expected that the total number of PTAs in force approaches 300 by the end of $2005 .^{1}$ The prevalence of PTAs also stimulates a surge of economic research on PTAs. One of main concerns is whether or not PTA formation contributes to global trade liberalization. Ohyama (1972) and Kemp and Wan (1976) demonstrate the possibility that Customs Union (CU) formation leads to global free trade. Panagariya and Krishna (2002) address the same question with regard to Free Trade Areas (FTAs). Furusawa and Konishi (2004, 2005) examine the stability of global free trade as a network of PTAs.

In recent years, most PTAs appear to take the form of FTAs rather than CUs. The main difference between CUs and FTAs is that member countries are allowed to choose different external tariff rates under FTAs, whereas they must choose the same external tariff rates under CUs. Countries have wider discretion and hence can negotiate with other countries more easily under FTAs, which must be one of the main reasons why countries prefer FTAs over CUs as the form of PTAs.

In the absence of any restriction, if FTA member countries specify different external tariff rates on the same good, the good enters the FTA exclusively through the country that specifies the lowest tariff rate. Higher tariff rates specified by other member countries are ineffective, and those countries that specify the higher tariff rates lose the opportunity to earn tariff revenues. Then, every member country tries to undercut other countries' external tariff rates in order to capture tariff revenues. Tariff revenue competition thus emerges.

To prevent this unintended effect, FTAs are usually equipped with the Rules of Origin (ROO) that prohibit trade deflection such that a good is imported to an FTA

\footnotetext{
${ }^{1}$ See the WTO's web site at http://www.wto.org/.
} 
member country from the Rest of the World (ROW) through another member country that specifies a lower external tariff rate. However, Shibata (1967) argues that FTA member countries can circumvent ROO by exporting the products that are domestically produced to the other member country while importing the same amount of the good from the ROW. That is, trade deflection effectively arises even in the presence of ROO, although it may only cause partial effects as it is bound by total supply within the FTA.

Since trade deflection can effectively exist, tariff revenue competition may arise as in the case without ROO. In fact, Richardson (1995) derives a surprising result that when two symmetric large countries form an FTA choosing external tariff rates non-cooperatively, there exists either no pure-strategy Nash equilibrium or a unique pure-strategy Nash equilibrium in which both countries choose zero tariff rates. Each member country has an incentive to capture the entire tariff revenues by choosing a tariff slightly lower than that of the partner country, so that the situation in which both countries set positive tariffs will not be sustained.

Richardson (1995) also conjectures without building an explicit model that if member countries are asymmetric in the market size, there exists a pure-strategy Nash equilibrium in which both countries set positive external tariffs. Richardson (1995, p. 1435) writes "If one partner is relatively large then an asymmetric equilibrium with positive tariffs is possible as this country may choose to bear the other's free-riding in order to reap external terms of trade gains. This has the empirical implication that a FTA is more tenable where one member country is large and, indeed, many actual FTAs have this structure." Since this observation is important both theoretically and empirically, it is essential to formally build an FTA model with asymmetric countries and prove this claim of Richardson (1995). This paper aims to complete this task. ${ }^{2}$

\footnotetext{
${ }^{2}$ Cadot et al. (1999) examine a similar tariff-setting game between two small member countries of an FTA in a political economy context developed by Grossman and Helpman (1994), and obtain a similar result to ours such that one country eliminates its tariff while the other maintains a positive tariff.
} 
The rest of the paper is organized as follows. After setting out the model in Section 2, Section 3 examines the tariff setting game between two FTA member countries in the absence of ROO. In this benchmark model, we find that both countries completely eliminate their individual external tariffs in a unique pure-strategy equilibrium. Section 4 analyzes the tariff revenue competition between the two FTA member countries in the presence of ROO. In the special case of symmetric member countries, we confirm Richardson's (1995) results that there exists either no pure-strategy Nash equilibrium or a unique pure-strategy Nash equilibrium in which both countries choose zero tariff rates. We also characterize the mixed-strategy equilibrium in the case of symmetric countries. Then in the case of asymmetric countries, we formally confirm his conjecture that that the two countries choose positive tariffs when they are sufficiently different in the market size. The relatively larger country is "willing" to sacrifice its tariff revenues in order to improve the terms of trade against the ROW. Section 5 provides concluding remarks.

\section{The Model}

In order to focus on the partial trade deflection, we consider trade of a homogeneous good imported by both countries that form an FTA. Two countries, 1 and 2, and the rest of the world (ROW) trade a competitively-produced homogenous good without any transport costs.

Countries 1 and 2 are identical except for their relative size. Total demand and total supply functions of these two countries as a whole are given by a decreasing function $D$ and an increasing function $S$, respectively. The relative size of country 1 is given by $\alpha \in(0,1 / 2]$, so the demand and supply in country 1 are given by $D_{1}(p)=\alpha D(p)$ and $S_{1}(p)=\alpha S(p)$, where $p$ denotes the domestic price for the homogenous good. Similarly, demand and supply in country 2 are given by $D_{2}(p)=(1-\alpha) D(p)$ and 
$S_{2}(p)=(1-\alpha) S(p)$, respectively. Each of the two countries imports this homogenous good and levies a non-negative tariff $t_{i}, i=1,2$. The export from the ROW is given by an increasing function $X$ of the world price. Countries 1 and 2 form an FTA: They mutually abolish tariffs imposed on the good that are traded between themselves, while setting their individual external tariffs against the ROW. The FTA is large enough to affect the world price $p_{W}$.

\section{Free Trade Area without the Rules of Origin}

To clarify the role of ROO, we first consider the benchmark case in which countries 1 and 2 form an FTA without ROO. Suppose now that the two countries have set different external tariffs on imports from the ROW. Since there is no trade friction between the FTA member countries, all the imports from the ROW that are consumed in the country with a higher external tariff are imported through its partner country with a lower tariff. Thus, the higher tariff rate selected by one member country is ineffective, and the price within the FTA is simply the world price $p_{W}$ plus the lower external tariff rate.

Due to the trade deflection caused by a difference in the external tariff rates, prices are equalized between the member countries but tariff revenues are distributed disproportionately. The country with a higher external tariff rate obtains no tariff revenues, while the country with a lower external tariff rate earns additional tariff revenues from the imports that are re-exported to the other member country. Consequently, each member country has an incentive to set a tariff lower than its FTA partner in order to earn these additional tariff revenues.

It is important which of the two member countries chooses a lower external tariff. We define functions $L\left(t_{1}, t_{2}\right)$ and $H\left(t_{1}, t_{2}\right)$ that identify the countries with a lower tariff 
rate and higher tariff rate, respectively:

$$
\begin{aligned}
& L\left(t_{1}, t_{2}\right)= \begin{cases}1 & \text { if } t_{1} \leq t_{2} \\
2 & \text { if } t_{1}>t_{2},\end{cases} \\
& H\left(t_{1}, t_{2}\right)= \begin{cases}1 & \text { if } t_{1}>t_{2} \\
2 & \text { if } t_{1} \leq t_{2},\end{cases}
\end{aligned}
$$

We call the country with a lower tariff rate "country $L$ " and the country with a higher tariff rate "country $H$." Note that when the two countries choose the same tariff rate, country 1 is called country $L$ for the sake of concreteness.

Once the two countries set their individual external tariffs, the world price is determined so that the excess demand within the FTA matches with the export supply from the ROW. Since the local price is given by $p_{W}+t_{L\left(t_{1}, t_{2}\right)}$ in either country within the FTA, the equilibrium condition is given by

$$
D\left(p_{W}+t_{L\left(t_{1}, t_{2}\right)}\right)-S\left(p_{W}+t_{L\left(t_{1}, t_{2}\right)}\right)=X\left(p_{W}\right)
$$

We call $p_{W}$ that satisfies this equality $p_{W}^{o}\left(t_{L\left(t_{1}, t_{2}\right)}\right)$. Henceforth, we suppress the arguments of $L\left(t_{1}, t_{2}\right)$ and $H\left(t_{1}, t_{2}\right)$ so that $t_{L}$, for example, signifies the tariff rate imposed by country $L\left(t_{1}, t_{2}\right)$.

Each country's payoff is measured by the total surplus derived from the transaction of the good in question. The payoff depends heavily on whether or not the country chooses a lower tariff than its partner. Let us first specify the equilibrium payoffs when $t_{1} \neq t_{2}$. The equilibrium payoff for country $L$ is given by the sum of the consumer surplus, producer surplus, and tariff revenues from the total imports by both member countries:

$w_{L}^{o}\left(t_{L}\right) \equiv \int_{p_{W}^{o}\left(t_{L}\right)+t_{L}}^{\infty} D_{L}(p) d p+\int_{0}^{p_{W}^{o}\left(t_{L}\right)+t_{L}} S_{L}(p) d p+t_{L}\left[D\left(p_{W}^{o}\left(t_{L}\right)+t_{L}\right)-S\left(p_{W}^{o}\left(t_{L}\right)+t_{L}\right)\right]$ 
Country $H$, on the other hand, earns no tariff revenues because its entire imports come from its FTA partner. Country $H$ 's equilibrium payoff is given by

$$
W_{H}^{o}\left(t_{L}\right) \equiv \int_{p_{W}^{o}\left(t_{L}\right)+t_{L}}^{\infty} D_{H}(p) d p+\int_{0}^{p_{W}^{o}\left(t_{L}\right)+t_{L}} S_{H}(p) d p
$$

Note that its payoff is independent of its own external tariff. Country $H$ 's tariff plays absolutely no role in this situation.

When $t_{1}=t_{2}$, it is indeterminate how the imports from the ROW will be allocated between the member countries. It may be the case that all the imports from the ROW are supplied to country 2 through country 1 or that each country imports directly from the ROW. We assume for the expositional simplicity that each member country $i$ imports the good in the amount that exactly satisfies its import demand, i.e., $D_{i}\left(p_{W}^{o}\left(t_{i}\right)+t_{i}\right)-S_{i}\left(p_{W}^{o}\left(t_{i}\right)+t_{i}\right)$. The following argument would not change qualitatively even with any alternative allocation rule of the imports from the ROW. Country $i$ 's payoff in this case can be written as

$$
v_{i}^{o}\left(t_{i}\right) \equiv \int_{p_{W}^{o}\left(t_{i}\right)+t_{i}}^{\infty} D_{i}(p) d p+\int_{0}^{p_{W}^{o}\left(t_{i}\right)+t_{i}} s_{i}(p) d p+t_{i}\left[D_{i}\left(p_{W}^{o}\left(t_{i}\right)+t_{i}\right)-S_{i}\left(p_{W}^{o}\left(t_{i}\right)+t_{i}\right)\right] .
$$

We now derive the best response functions of countries 1 and 2. Define the tariff rate that maximizes $w_{i}^{o}, i=1,2$, by

$$
t_{i}^{o} \in \arg \max w_{i}^{o}\left(t_{i}\right)
$$

The best response to $t_{-i}$ (where $-i$ means $j \neq i$ ) equals $t_{i}^{o}$ if $t_{-i}>t_{i}^{o}$. If $0<t_{-i} \leq t_{i}^{o}$, on the other hand, country $i$ 's best response to $t_{-i}$ is to undercut $t_{-i}$. If country $i$ chooses its tariff lower than $t_{-i}$, in this case, it chooses a tariff that is just below $t_{-i}$. This is because country $i$ wants to choose its tariff as high as possible, or as close as possible, to $t_{i}^{o}$. Expressing this tariff rate by $t_{i}=t_{-i}-\epsilon$, where $\epsilon$ is an arbitrarily small positive number, the payoff in this situation is given by $w_{i}^{o}\left(t_{-i}-\epsilon\right)$. If country $i$ sets $t_{i}=t_{-i}$, its payoff equals $v_{i}^{o}\left(t_{i}\right)$. Since $w_{i}^{o}\left(t_{i}\right)$ is greater than $v_{i}^{o}\left(t_{i}\right)$ by the tariff revenues accrued 
from country $-i$ 's imports, we see that country $i$ prefers undercutting $t_{-i}$ to setting $t_{i}=t_{-i}$, i.e., $w_{i}^{o}\left(t_{i}-\epsilon\right)>v_{i}^{o}\left(t_{i}\right)$. Finally, if country $i$ chooses its tariff rate higher than $t_{-i}$, its payoff becomes $W_{i}^{o}\left(t_{-i}\right)$. As is evident from (2) and (3), country $L$ 's payoff is higher than country $H$ 's by the amount of tariff revenues, so $w_{i}^{o}\left(t_{-i}-\epsilon\right)>W_{i}^{o}\left(t_{-i}\right)$ if $\epsilon$ is sufficiently small. Therefore, the best response to $t_{-i}$ in this case is given by $t_{i}=t_{-i}-\epsilon$ for $t_{-i}>0$. The best response to $t_{-i}=0$ takes any value in the range of $[0, \infty)$ since country $i$ 's payoff is $W_{i}(0)$ regardless of its own tariff rate $t_{i}$.

Figure 1 depicts the best response curves of the two countries, $B_{1}$ and $B_{2}$, for $\alpha=1 / 2$, i.e., for the case of symmetric countries. As the figure shows, $\left(t_{1}, t_{2}\right)=(0,0)$ is a unique Nash equilibrium. Since the qualitative features of the best response curves do not change even when the countries are asymmetric, free trade remains a unique Nash equilibrium in the asymmetric case. In the absence of ROO, FTA formation induces a tariff revenue competition, and as a result free trade under which both countries earn zero tariff revenues prevails in equilibrium.

\section{Free Trade Area with the Rules of Origin}

We now turn to the case with ROO that prevents the goods imported by one member country from the ROW from being re-exported to the other member country. As Shibata (1967) argues, however, member countries can circumvent ROO by exporting the products that are domestically produced to the other member country and importing the same amount of the good from the ROW. That is, trade deflection effectively arises.

When tariff rates differ between the two countries, trade is effectively deflected through country $L$. There are three cases to be considered. The first case (called case A) is the one in which the demand in country $H$ is so large that the total supply in the FTA does not suffice to satisfy all the demands in country $H$. In this case, country $H$ as well as country $L$ imports the good from the ROW. In the second case (called 
case B), the total supply in the FTA just meets the demand in country $H$, so country $H$ imports the good only from country $L$. Finally in case $\mathrm{C}$, the demands in country $H$ are so small that part of the supply in the FTA is directed to country $L$. Effective trade deflection is most prominent in case $\mathrm{C}$ and least prominent in case $\mathrm{A}$.

\subsection{The three Cases}

In case $\mathrm{A}$, the demands in country $H$ are sufficiently large that the total production within the FTA does not satisfy all the demands in country $H$ at the price $p_{W}+t_{H}$, i.e., $D_{H}\left(p_{W}+t_{H}\right)>S\left(p_{W}+t_{H}\right)$. As Figure 2 depicts, country $H$ as well as country $L$ imports the good from the ROW; The amount of country H's imports from the ROW is measured by the horizontal distance between the $D_{H}$ curve and the $S$ curve at $p_{W}+t_{H}$. Since countries $L$ and $H$ both import the good from the ROW, the domestic prices are $p_{W}+t_{L}$ and $p_{W}+t_{H}$ in countries $L$ and $H$, respectively. All of the good produced in country $L$ are thus exported to country $H$, while the demands in country $L$ are satisfied by the imports from the ROW. The world equilibrium price $p_{W}^{A}\left(t_{1}, t_{2}\right)$ is given by $p_{W}$ that satisfies

$$
D_{H}\left(p_{W}+t_{H}\right)+D_{L}\left(p_{W}+t_{L}\right)=S_{H}\left(p_{W}+t_{H}\right)+S_{L}\left(p_{W}+t_{H}\right)+X\left(p_{W}\right) .
$$

Since $D$ is a decreasing function and $S$ and $X$ are increasing functions, $p_{W}^{A}\left(t_{1}, t_{2}\right)$ is decreasing both in $t_{1}$ and $t_{2}$ while $p_{W}^{A}\left(t_{1}, t_{2}\right)+t_{1}$ and $p_{W}^{A}\left(t_{1}, t_{2}\right)+t_{2}$ are increasing in $t_{1}$ and $t_{2}$, respectively.

The consumer surplus and tariff revenues in country $L$ when $t_{1} \neq t_{2}$ are shown as $L_{1}$ and $L_{3}$ in the left diagram of Figure 2, while the producer surplus is depicted as $L_{2}$ in the right diagram of Figure $2{ }^{3}$ Social welfare of country $L$ is given by

$$
w_{L}^{A}\left(t_{1}, t_{2}\right)=\int_{p_{W}^{A}\left(t_{1}, t_{2}\right)+t_{L}}^{\infty} D_{L}(p) d p+\int_{0}^{p_{W}^{A}\left(t_{1}, t_{2}\right)+t_{H}} S_{L}(p) d p+t_{L} D_{L}\left(p_{W}^{A}\left(t_{1}, t_{2}\right)+t_{L}\right)
$$

\footnotetext{
${ }^{3}$ Since the supply from country $L$ is equal to the horizontal distance between the total supply curve within the FTA, $S$, and the supply curve of country $H, S_{H}$, the producer surplus in country $L$ can be drawn in the diagram for country $H$, as depicted in Figure 2.
} 
Social welfare of country $H$, on the other hand, is measured in Figure 2 as the sum of the consumer surplus $H_{1}$, producer surplus $H_{2}$, and tariff revenues $H_{3}$, which is given by

$$
\begin{aligned}
W_{H}^{A}\left(t_{1}, t_{2}\right)= & \int_{p_{W}^{A}\left(t_{1}, t_{2}\right)+t_{H}}^{\infty} D_{H}(p) d p+\int_{0}^{p_{W}^{A}\left(t_{1}, t_{2}\right)+t_{H}} S_{H}(p) d p \\
& +t_{H}\left[D_{H}\left(p_{W}^{A}\left(t_{1}, t_{2}\right)+t_{H}\right)-S\left(p_{W}^{A}\left(t_{1}, t_{2}\right)+t_{H}\right)\right] .
\end{aligned}
$$

Given that each member country imports the good in the amount that exactly satisfies its import demand when the two countries set the same tariff rate, country $i$ 's social welfare when $t_{1}=t_{2} \equiv t$ equals

$$
v_{i}^{A}(t)=\int_{p_{W}^{A}(t, t)+t}^{\infty} D_{i}(p) d p+\int_{0}^{p_{W}^{A}(t, t)+t} S_{i}(p) d p+t\left[D_{i}\left(p_{W}^{A}(t, t)+t\right)-S_{i}\left(p_{W}^{A}(t, t)+t\right)\right] .
$$

Now, we turn to case B, in which the demands in country $H$ are moderate such that $D_{H}\left(p_{W}+t_{H}\right) \leq S\left(p_{W}+t_{H}\right)$ and $D_{H}\left(p_{W}+t_{L}\right) \geq S\left(p_{W}+t_{L}\right)$ simultaneously hold. As shown in the right diagram of Figure 3, the domestic price in country $H$ is not given by $p_{W}+t_{H}$ in this case but rather given by $p_{H}^{*}$, where $p_{H}^{*}$ is defined so as to satisfy $D_{H}\left(p_{H}^{*}\right)=S\left(p_{H}^{*}\right)$. At this price $p_{H}^{*}$, the total production within the FTA just satisfies the demand in country $H$. Unlike in case A, country $H$ does not directly import the good from the ROW. The domestic price in country $L$ is still equal to $p_{W}+t_{L}$. As $p_{H}^{*}>p_{W}+t_{L}$, all of the good produced in country $L$ are exported to country $H$, while as in case $\mathrm{A}$, the demand in country $L$ is completely satisfied by the imports from the ROW. As Figure 3 shows, the tariff rate set by country $H$ is totally ineffective in this case. The equilibrium world price, which is determined by

$$
D_{L}\left(p_{W}+t_{L}\right)=X\left(p_{W}\right)
$$

is a function of $t_{L}$ only and can be expressed as $p_{W}=p_{W}^{B}\left(t_{L}\right)$. The equilibrium world price $p_{W}^{B}$ is a decreasing function such that $p_{W}^{B}\left(t_{L}\right)+t_{L}$ is increasing in $t_{L}$.

Social welfare of country $L$ when $t_{1} \neq t_{2}$ is again the sum of the consumer surplus, tariff revenues ( $L_{1}$ and $L_{3}$ in the left diagram of Figure 3, respectively), and producer 
surplus $\left(L_{2}\right.$ in the right diagram of Figure 3). Social welfare of country $L, w_{L}^{B}$, is a function of $t_{L}$, which is given by

$$
w_{L}^{B}\left(t_{L}\right)=\int_{p_{W}^{B}\left(t_{L}\right)+t_{L}}^{\infty} D_{L}(p) d p+\int_{0}^{p_{H}^{*}} S_{L}(p) d p+t_{L} D_{L}\left(p_{W}^{B}\left(t_{L}\right)+t_{L}\right)
$$

Social welfare of country $H$ is the sum of the consumer surplus $H_{1}$ and producer surplus $\mathrm{H}_{2}$ and is given by

$$
W_{H}^{B}=\int_{p_{H}^{*}}^{\infty} D_{H}(p) d p+\int_{0}^{p_{H}^{*}} S_{H}(p) d p .
$$

Note that social welfare of country $H$ is independent of the tariff profile.

As for the case in which $t_{1}=t_{2} \equiv t$, we first observe that there are only two tariff rates, one that satisfies $p_{W}^{B}(t)+t=p_{1}^{*}$ and the other that satisfies $p_{W}^{B}(t)+t=p_{2}^{*}$, which correspond to case B. In either case, the domestic prices are the same between the two countries, so country $i$ 's social welfare can be written as

$$
v_{i}^{B}(t)=\int_{p_{W}^{B}(t)+t}^{\infty} D_{i}(p) d p+\int_{0}^{p_{W}^{B}(t)+t} S_{i}(p) d p+t\left[D_{i}\left(p_{W}^{B}(t)+t\right)-S_{i}\left(p_{W}^{B}(t)+t\right)\right] .
$$

Finally in case $\mathrm{C}$, the demands in country $H$ are so small that $D_{H}\left(p_{W}+t_{L}\right)<$ $S\left(p_{W}+t_{L}\right)$ holds. The demands in country $H$ are completely satisfied by the supply within the FTA and hence country $H$ does not import directly from the ROW, which is qualitatively the same as case B. Unlike in case B, however, part the good produced in country $L$ is consumed in country $L$, so that the producer price as well as the consumer price in country $L$ (as well as in country $H$ ) is equal to $p_{W}+t_{L}$. The amount of the good produced and consumed domestically in country $L$ is shown in Figure 4 as the horizontal distance between the $S$ and $D_{H}$ curves at the price $p_{L}=p_{W}+t_{L}$. Country $L$ 's imports are smaller than $D_{L}\left(p_{W}+t_{L}\right)$ by this amount as shown by the reduction of tariff revenues in the left diagram of Figure 4. The equilibrium world price $p_{W}^{C}\left(t_{L}\right)$ is $p_{W}$ that satisfies

$$
D\left(p_{W}+t_{L}\right)=S\left(p_{W}+t_{L}\right)+X\left(p_{W}\right)
$$


which does not depend on $t_{H}$ as in case B. Again, $p_{W}^{C}\left(t_{L}\right)$ is a decreasing function such that $p_{W}^{C}\left(t_{L}\right)+t_{L}$ is increasing in $t_{L}$.

Social welfare of country $L$ when $t_{1} \neq t_{2}$ is measured as the sum of the consumer surplus $L_{1}$, producer surplus $L_{2}$, and tariff revenue $L_{3}$. Social welfare of country $H$, on the other hand, is the sum of consumer surplus $H_{1}$ and producer surplus $H_{2}$. Social welfare functions of countries $L$ and $H$ are respectively given by

$$
\begin{aligned}
w_{L}^{C}\left(t_{L}\right)= & \int_{p_{W}^{C}\left(t_{L}\right)+t_{L}}^{\infty} D_{L}(p) d p+\int_{0}^{p_{W}^{C}\left(t_{L}\right)+t_{L}} S_{L}(p) d p \\
& +t_{L}\left[D\left(p_{W}^{C}\left(t_{L}\right)+t_{L}\right)-S\left(p_{W}^{C}\left(t_{L}\right)+t_{L}\right)\right], \\
W_{H}^{C}\left(t_{L}\right)= & \int_{p_{W}^{C}\left(t_{L}\right)+t_{L}}^{\infty} D_{H}(p) d p+\int_{0}^{p_{W}^{C}\left(t_{L}\right)+t_{L}} S_{H}(p) d p .
\end{aligned}
$$

Country $i$ 's social welfare when $t_{1}=t_{2} \equiv t$ equals

$$
v_{i}^{C}(t)=\int_{p_{W}^{C}(t)+t}^{\infty} D_{i}(p) d p+\int_{0}^{p_{W}^{C}(t)+t} S_{i}(p) d p+t\left[D_{i}\left(p_{W}^{C}(t)+t\right)-S_{i}\left(p_{W}^{C}(t)+t\right)\right] .
$$

\subsection{Best Response Functions}

To derive the best response functions for each member country, we first examine which of the three cases is relevant for each feasible tariff profile. If the tariffs are high for both countries, the good will not be imported from the ROW, so the domestic prices for member countries are $\bar{p}$, where $\bar{p}$ is given by $D(\bar{p})=S(\bar{p})$ as shown in Figure 5 . We see from (10) that the import of the FTA from the ROW ceases when $t_{L}$ is as high as $X\left(p_{W}^{C}\left(t_{L}\right)\right)=0$. We call such a tariff rate $\bar{t}$, which is clearly common to both countries 1 and 2. The shaded area in Figure 6 corresponds to this case.

Next, we derive the border between cases $\mathrm{B}$ and $\mathrm{C}$ in the feasible set of tariff profiles. Let $t_{L}^{B C}$ denote $t_{L}$ that satisfies $p_{W}^{B}\left(t_{L}\right)+t_{L}=p_{H}^{*}$. Since $D_{H}\left(p_{H}^{*}\right)=S\left(p_{H}^{*}\right)$ by the definition of $p_{H}^{*}$, we see form (7) and (10) that $p_{W}^{C}\left(t_{L}^{B C}\right)+t_{L}^{B C}=p_{H}^{*}$ also holds. Then, since $p_{W}^{C}\left(t_{L}\right)+t_{L}$ is increasing in $t_{L}, p_{W}^{C}\left(t_{L}\right)+t_{L}>p_{H}^{*}$ holds if $t_{L}>t_{L}^{B C}$, i.e., the non-prohibitive tariff profile that satisfies $t_{L}>t_{L}^{B C}$ corresponds to case $\mathrm{C}$ as Figure 6 depicts. 
If $t_{L}<t_{L}^{B C}$, on the other hand, $p_{W}^{B}\left(t_{L}\right)+t_{L}<p_{H}^{*}$ holds, so $p_{W}+t_{H} \leq p_{H}^{*}$ if $t_{H}$ is close to $t_{L}$, but otherwise $p_{W}+t_{H}>p_{H}^{*}$. Let us define $t_{H}^{A B}\left(t_{L}\right)$ as $t_{H}$ that satisfies $p_{W}^{B}\left(t_{L}\right)+t_{H}=p_{H}^{*}$. Since $p_{W}^{B}\left(t_{L}\right)$ is decreasing in $t_{L}, t_{H}^{A B}\left(t_{L}\right)$ is increasing in $t_{L}$ as depicted in Figure 6. It also follows from (4), (7), and the definition of $p_{H}^{*}$ that $p_{W}^{A}\left(t_{L}, t_{H}^{A B}\left(t_{L}\right)\right)+t_{H}^{A B}\left(t_{L}\right)=p_{H}^{*}$. If $t_{H}<t_{H}^{A B}\left(t_{L}\right)$, then $p_{W}^{A}\left(t_{L}, t_{H}\right)+t_{H}<p_{H}^{*}$ so $\left(t_{L}, t_{H}\right)$ corresponds to case $\mathrm{A}$, whereas if $t_{H} \geq t_{H}^{A B}\left(t_{L}\right), p_{W}^{B}\left(t_{L}\right)+t_{H}>p_{H}^{*}$ so $\left(t_{L}, t_{H}\right)$ corresponds to case B.

We have shown the following lemma, which is reflected in Figure 6.

Lemma 1 If $t_{L} \geq \bar{t}$, the FTA does not import the good from the $R O W$. Any tariff profile such that $t_{L}^{B C}<t_{L}<\bar{t}$ corresponds to case C. For $t_{L} \leq t_{L}^{B C}$, the tariff profile such that $t_{H} \geq t_{H}^{A B}\left(t_{L}\right)$ corresponds to case $B$, whereas the tariff profile such that $t_{H}<t_{H}^{A B}\left(t_{L}\right)$ corresponds to case $A$.

If the external tariffs imposed by the two countries are large, the demands for the good in the FTA from the ROW are small so that all the imports from the ROW enter the FTA through country $L$ (cases B and C). If the external tariffs are small, on the other hand, country $H$ also imports the good directly from the ROW, so its tariff rate affects the world price.

Now, we derive the best response function for each member country. In addition to the usual trade off between improving the terms of trade and creating distortions, each member country considers whether or not to undercut the partner's tariff so that it captures all the tariff revenues that accrue to the entire FTA. If the partner country's tariff rate is high, the country optimally sets a lower tariff rate than its partner's. If the partner country's tariff rate is in an intermediate range, the country is better off by undercutting its partner's external tariff rate in order to capture the entire tariff revenues. The incentive to undercut its partner's tariff may remain even when its partner's tariff is negligible. In order to improve the terms of trade against the ROW, 
however, a country may have an incentive to set a higher tariff rate than its partner's tariff when its partner's tariff is very small, even though the country loses tariff revenues by doing so.

Let us begin with the case in which the partner country's tariff rate is high. Consider the case in which the partner country $-i$ 's tariff rate is greater than or equal to $\bar{t}$. As we see from Figure 6, case $\mathrm{C}$ prevails if country $i$ selects $t_{i}$ from the set $\left(t_{i}^{B C}, \bar{t}\right)$, while case B prevails if it selects $t_{i}$ below $t_{i}^{B C}$. Country $i$ will never selects a prohibitive tariff rate since trade with the ROW is beneficial.

In either case, country $i$ selects a lower tariff rate than country $-i$, and hence it is faced with the usual trade off between improving the terms of trade and creating distortion. The larger is country $i$, the greater is the optimal tariff due to the greater market power that country $i$ can exercise. Thus, it is likely to select a tariff rate higher than $t_{i}^{B C}$, so case $\mathrm{C}$ follows. Indeed, if country $i$ is large (so country $-i$ is small), $p_{-i}^{*}$ is small, so that $p_{W}+t_{i}$ is likely to exceed $p_{-i}^{*}$, which is a characteristic of case C. In this case, country $i$ optimally selects

$$
\tau_{i}^{C} \in \arg \max w_{i}^{C}\left(t_{i}\right)
$$

If country $i$ is small, on the other hand, the terms-of-trade motivation is relatively small so country $i$ selects $\tau_{i}^{B}$ below $t_{i}^{B C}$ such that

$$
\tau_{i}^{B} \in \arg \max w_{i}^{B}\left(t_{i}\right)
$$

Note that neither $\tau_{i}^{B}$ nor $\tau_{i}^{C}$ depends on $t_{-i}$, so it is expected that it continues to be the best response to $t_{-i}$ as long as the tariff profile lies in the same region, $\mathrm{B}$ or $\mathrm{C}$, with $t_{i}<t_{-i}$. Indeed, we show that (i) if $\tau_{i}^{C}$ is the best response to $t_{-i} \geq \bar{t}$, it is also the best response as long as country $i$ 's tariff rate is smaller than the other, i.e., $t_{-i}>\tau_{i}^{C}$, and (ii) if $\tau_{i}^{B}$ is the best response to $t_{-i} \geq \bar{t}$, it is also the best response as 
long as $t_{-i}>t_{-i}^{A B}\left(\tau_{i}^{B}\right)$, while

$$
\tau_{i}^{A}\left(t_{-i}\right) \in \arg \max _{t_{i}} w_{i}^{A}\left(t_{i}, t_{-i}\right)
$$

is the best response if $t_{-i}$ is smaller than or equal to $t_{-i}^{A B}\left(\tau_{i}^{B}\right)$ with $\tau_{i}^{A}\left(t_{-i}\right)<t_{-i}$. Let $\bar{\tau}_{-i}$ denote country $-i$ 's tariff rate such that country $i$ 's reaction curve meets the 45 degree line when $t_{-i}=\bar{\tau}_{-i}$.

Since $\tau_{i}^{C}, \tau_{i}^{B}$, and $\tau_{i}^{A}\left(t_{-i}\right)$ are country $i$ 's best responses given that $t_{i}<t_{-i}$, the only possibility that country $i$ selects a different tariff rate in response to $t_{-i}$ is the case in which country $i$ selects a higher tariff rate than its partner's so as to improve the terms of trade. Let us define country $i$ 's best response function in this case by

$$
\tilde{\tau}_{i}^{A}\left(t_{-i}\right) \in \arg \max _{t_{i}} W_{i}^{A}\left(t_{i}, t_{-i}\right)
$$

We show in the Appendix that selecting $\tilde{\tau}_{i}^{A}\left(t_{-i}\right)$ will never be the best response when $t_{-i} \in\left(\bar{\tau}_{-i}, \infty\right)$. Since the partner's tariff rate is sufficiently high, country $i$ prefers capturing the entire tariff revenues by setting a lower tariff rate to further improving the terms of trade by setting a higher tariff rate thereby sacrificing the tariff revenues. Given this observation, we have proved the following lemma.

Lemma 2 Country i's best response to $t_{-i} \in\left(\bar{\tau}_{-i}, \infty\right)$ is either (i) $\tau_{i}^{C}$ or (ii) $\tau_{i}^{A}\left(t_{-i}\right)$ for $t_{-i} \in\left(\bar{\tau}_{-i}, t_{-i}^{A B}\left(\tau_{i}^{B}\right)\right)$ and $\tau_{i}^{B}$ for $t_{-i} \in\left[t_{-i}^{A B}\left(\tau_{i}^{B}\right), \infty\right)$.

When $t_{-i}=\bar{\tau}_{-i}$, country $i$ prefers undercutting $t_{-i}$ to setting the same tariff rate as its partner's. Recall that $v_{i}^{k}(t)$ denotes country $i$ 's social welfare when $t_{1}=t_{2}=t$ in case $k$ (where $k=A, B, C$ ). Since capturing tariff revenues is certainly beneficial, it is immediate that $w_{i}^{A}(t, t)>v_{i}^{A}(t)$ and similarly for other cases. Since the same argument applies to $t_{-i}$ that is smaller than $\bar{\tau}_{-i}$ by continuity, we have the following lemma. 
Lemma 3 There exists a tariff rate $\underline{\tau}_{-i}$ such that if $t_{-i} \in\left(\underline{\tau}_{-i}, \bar{\tau}_{-i}\right]$, country $i$ 's best response is to undercut $t_{-i}$.

Tariff revenue competition emerges in the intermediate range of the tariff rate.

In this range of the tariff rate, country $i$ 's tariff rate decreases as its partner's tariff decreases, worsening the terms of trade and lowering the tariff revenues. In the case where regions $\mathrm{A}$ and $\mathrm{B}$ below the 45 degree line in Figure 6 disappear when $\alpha$ is very small, country 1 may have to sit and watch this situation. For country 1, as the smaller country, is not able to affect the world price by setting a higher tariff rate than country 2 in this case. Therefore, its best response is to undercut $t_{2}$ if $t_{2} \in\left(0, \bar{\tau}_{2}\right]$ and select any tariff rate from $[0, \infty)$ if $t_{2}=0$ since $t_{1}$ will not affect the equilibrium. But in other cases, as the partner country's tariff rate decreases, the incentive to choose a higher tariff to improve the terms of trade becomes stronger even though the country would lose some tariff revenues as a result.

There are two cases to be distinguished depending on the sign of $\left(\partial W_{i}^{A} / \partial t_{i}\right)(0,0)$. When both countries choose zero external tariff rates, it may appear that the relatively larger country can improve its social welfare by raising its external tariff. However, in addition to the usual second-order distortion, there is a negative first-order effect that improvement of the terms of trade is "leaked" to its partner country. To see this claim, we differentiate $W_{i}^{A}$ with respect to $t_{i}$ and evaluate the partial derivative at $\left(t_{1}, t_{2}\right)=(0,0)$ to obtain

$$
\frac{\partial W_{i}^{A}}{\partial t_{i}}(0,0)=-\frac{\partial p_{W}^{A}}{\partial t_{i}}(0,0)\left[D_{i}\left(p_{W}^{A}(0,0)\right)-S_{i}\left(p_{W}^{A}(0,0)\right)\right]-S_{-i}\left(p_{W}^{A}(0,0)\right) .
$$

The first term on the right-hand side is the positive terms-of-trade effect and the second term shows the leakage of the terms-of-trade effect to the other member country. Thus, if (i) country $i$ 's tariff has little effect on the terms of trade, i.e., $\left|\partial p_{W}^{A} / \partial t_{i}\right|$ is small, and (ii) country $i$ is small so that $D_{i}\left(p_{W}^{A}(0,0)\right)-S_{i}\left(p_{W}^{A}(0,0)\right)$ is small and $S_{-i}\left(p_{W}^{A}(0,0)\right)$ is large,$\left(\partial W_{i}^{A} / \partial t_{i}\right)(0,0)$ is likely to be negative. 
Now, if $\left(\partial W_{i}^{A} / \partial t_{i}\right)(0,0)>0$, country $i$ is better off by choosing a positive tariff rate in response to the partner country's zero tariff rate. By continuity, we find that the critical tariff rate $\underline{\tau}_{-i}$ is positive and country $i$ prefers setting $\tilde{\tau}_{i}^{A}\left(t_{-i}\right)$ to undercutting $t_{-i}$ if $t_{-i} \in\left[0, \underline{\tau}_{-i}\right]$. If $\left(\partial W_{i}^{A} / \partial t_{i}\right)(0,0) \leq 0$, on the other hand, country $i$ undercuts its partner's tariff as long as $t_{-i} \in\left(0, \bar{\tau}_{-i}\right]$, i.e., $\underline{\tau}_{-i}=0$, and sets $t_{i}=0$ in response to $t_{-i}=0$.

Lemma 4 If the two member countries are highly asymmetric in the size of the market, the smaller country, country 1 , undercuts its partner's tariff if $t_{2} \in\left(0, \bar{\tau}_{2}\right)$ and selects any $t_{1} \in[0, \infty)$ if $t_{2}=0$. Otherwise, if $\left(\partial W_{i}^{A} / \partial t_{i}\right)(0,0)>0$, then country $i$ selects $\tilde{\tau}_{i}^{A}\left(t_{-i}\right)$ if $t_{-i} \in\left[0, \underline{\tau}_{-i}\right]$. If $\left(\partial W_{i}^{A} / \partial t_{i}\right)(0,0) \leq 0$, on the other hand, country $i$ undercuts its partner's tariff if $t_{-i} \in\left(0, \bar{\tau}_{-i}\right]$ and sets $t_{i}=0$ if $t_{-i}=0$.

\subsection{Nash Equilibrium}

Having derived the best response functions, we now derive the Nash equilibrium of the tariff setting game between the two FTA member countries. The property of the Nash equilibrium differs considerably depending on the value of $\alpha$.

We first consider the case in which the countries are symmetric, i.e., $\alpha=1 / 2$. It mainly follows from Lemma 4 that if $\left(\partial W_{i}^{A} / \partial t_{i}\right)(0,0)>0$, the two countries' reaction curves do not intersect with each other as depicted in Figure 7, so there is no purestrategy Nash equilibrium. If $\left(\partial W_{i}^{A} / \partial t_{i}\right)(0,0) \leq 0$, on the other hand, $\left(t_{1}, t_{2}\right)=(0,0)$ is a unique pure-strategy equilibrium. We have confirmed this striking result obtained by Richardson (1995). By continuity, we have the following proposition.

Proposition 1 (Richardson, 1995) Suppose that the two countries are relatively similar in the market size. Then, in the case of inelastic terms of trade with respect to the external tariff set by the FTA members, there exists a unique pure-strategy Nash equilibrium in which both FTA member countries completely eliminate their individual 
external tariffs. In the case of elastic terms of trade with respect to the external tariffs, on the other hand, there is no pure-strategy Nash equilibrium.

Despite the fact that pure-strategy Nash equilibrium does not exist in the case of elastic terms of trade with respect to the external tariffs, there always exist mixedstrategy equilibria when the two countries are symmetric, i.e., $\alpha=1 / 2$. We show that there is a symmetric mixed-strategy equilibrium in which each country stochastically chooses its tariff rate from an interval. The strategy is characterized by the cumulative distribution function $F$ with a continuous density function $f$, defined on the support $\left[\underline{\tau}^{m}, \bar{\tau}^{m}\right]$, where $\underline{\tau}^{m}$ and $\bar{\tau}^{m}$ are determined such that $0<\underline{\tau}^{m}<\bar{\tau}^{m}<\bar{\tau}_{i}$. Note that $\bar{\tau}_{1}=\bar{\tau}_{2}$ in this case due to the symmetry.

To describe the equilibrium strategy, we let $w_{i}$ and $W_{i}$ denote country $i$ 's payoff when country $i$ selects a lower tariff and higher tariff than its partner, respectively. The function $w_{i}$, for example, is equivalent to either one of $w_{i}^{A}, w_{i}^{B}$, and $w_{i}^{C}$, depending on the tariff profile. Then, country $i$ 's expected payoff when it selects its tariff rate $t_{i}$ can be written as

$$
V\left(t_{i}\right)=\int_{\underline{\tau}^{m}}^{t_{i}} W_{i}\left(t_{i}, t_{-i}\right) f\left(t_{-i}\right) d t_{-i}+\int_{t_{i}}^{\bar{\tau}^{m}} w_{i}\left(t_{i}, t_{-i}\right) f\left(t_{-i}\right) d t_{-i} .
$$

The derivative of $V$ is readily obtained as

$$
\begin{aligned}
V^{\prime}\left(t_{i}\right)= & \int_{\underline{\tau}^{m}}^{t_{i}} \frac{\partial W_{i}}{\partial t_{i}}\left(t_{i}, t_{-i}\right) f\left(t_{-i}\right) d t_{-i}+\int_{t_{i}}^{\bar{\tau}^{m}} \frac{\partial w_{i}}{\partial t_{i}}\left(t_{i}, t_{-i}\right) f\left(t_{-i}\right) d t_{-i} \\
& -f\left(t_{i}\right)\left[w_{i}\left(t_{i}, t_{i}\right)-W_{i}\left(t_{i}, t_{i}\right)\right] .
\end{aligned}
$$

The first term represents the expected change of country $i$ 's payoff when country $i$ selects a higher tariff than its partner's. This payoff equals zero when the tariff profile corresponds to either case B or C, since the higher tariff will not affect equilibrium. The second term represents the expected change of the payoff when country $i$ selects a lower tariff. The expected change is positive as $t_{i}<\bar{\tau}_{i}$. The last term represents the 
expected loss of tariff revenues, such that if the tariff profile corresponds to case A, for example,

$$
w_{i}\left(t_{i}, t_{i}\right)-W_{i}\left(t_{i}, t_{i}\right)=w_{i}^{A}\left(t_{i}, t_{i}\right)-W_{i}^{A}\left(t_{i}, t_{i}\right)=t_{i} S\left(p_{W}^{A}\left(t_{i}, t_{i}\right)+t_{i}\right)
$$

For the distribution function $F$ to be the equilibrium strategy, country $i$ should be indifferent among all the tariffs in the support. Thus, we have from $V^{\prime}\left(t_{i}\right)=0$ the following equation that characterizes the equilibrium strategy.

$$
f\left(t_{i}\right)=\frac{\int_{\underline{\tau}^{m}}^{t_{i}} \frac{\partial W_{i}}{\partial t_{i}}\left(t_{i}, t_{-i}\right) f\left(t_{-i}\right) d t_{-i}+\int_{t_{i}}^{\bar{\tau}^{m}} \frac{\partial w_{i}}{\partial t_{i}}\left(t_{i}, t_{-i}\right) f\left(t_{-i}\right) d t_{-i}}{w_{i}\left(t_{i}, t_{i}\right)-W_{i}\left(t_{i}, t_{i}\right)}
$$

Substituting $\bar{\tau}^{m}$ for $t_{i}$ in (14), we obtain the density at the higher end of the support as

$$
f\left(\bar{\tau}^{m}\right)=\frac{\int_{\underline{\tau}^{m}}^{\bar{\tau}^{m}} \frac{\partial W_{i}}{\partial t_{i}}\left(\bar{\tau}^{m}, t_{-i}\right) f\left(t_{-i}\right) d t_{-i}}{w_{i}\left(\bar{\tau}^{m}, \bar{\tau}^{m}\right)-W_{i}\left(\bar{\tau}^{m}, \bar{\tau}^{m}\right)} .
$$

For any $\bar{\tau}^{m} \in\left(0, \bar{\tau}_{i}\right)$, the density at this endpoint is given by (15), and the density at any other tariff rate is consequently derived from (14). The proof of the claim that $\underline{\tau}^{m}>0$ is simple but technical, so it is relegated to the Appendix. We record the finding as a proposition.

Proposition 2 If the two countries are symmetric, i.e., $\alpha=1 / 2$, there exists a symmetric mixed-strategy equilibrium in which the two countries stochastically select their individual tariffs from the common interval $\left[\underline{\tau}^{m}, \bar{\tau}^{m}\right]$, where $0<\underline{\tau}^{m}<\bar{\tau}^{m}<\bar{\tau}_{i}$.

To gain insight into this mixed-strategy equilibrium, let us consider the case in which $\bar{\tau}_{i}>t_{i}^{B C}$. Country $i$ 's best response to a large $t_{-i}$ is to set its tariff at a relatively high level $\tau_{i}^{C}$, which in turn equals to $\bar{\tau}_{i}$, in this case. We select $\bar{\tau}^{m}$ at a level greater than $t_{i}^{B C}$. Then, as long as $t_{-i}$ is in the interval $\left(t_{-i}^{B C}, \bar{\tau}^{m}\right]$, case $\mathrm{B}$ or $\mathrm{C}$ prevails if $t_{i}>t_{-i}$ while only case $\mathrm{C}$ prevails if $t_{i} \leq t_{-i}$. So, we have $\left(\partial W_{i} / \partial t_{i}\right)\left(t_{i}, t_{-i}\right)=0$ and $\left(\partial w_{i} / \partial t_{i}\right)\left(t_{i}, t_{-i}\right)=w_{i}^{C \prime}\left(t_{i}\right)$. The equilibrium strategy density function given by (14) is reduced to

$$
f\left(t_{i}\right)=\frac{w_{i}^{C \prime}\left(t_{i}\right)\left[1-F\left(t_{i}\right)\right]}{w_{i}^{C}\left(t_{i}\right)-W_{i}^{C}\left(t_{i}\right)}
$$


Since $F\left(\bar{\tau}^{m}\right)=1$, we immediately obtain $f\left(\bar{\tau}^{m}\right)=0$. Moreover, we see that given that $F^{\prime}\left(t_{i}\right) \geq 0$, if (i) $w_{i}^{C^{\prime}}\left(t_{i}\right)>$ and (ii) tariff revenues increase with $t_{i}$ when $t_{i}<\tau_{i}^{C}$, the density $f\left(t_{i}\right)$ is a decreasing function in this range. (These two conditions are usually satisfied due to the trade off between improving the terms of trade and creating distortion when a country raises its external tariff.) Raising its external tariff rate, country $i$ benefits from the resulting improvement of the terms of trade but incurs a higher risk of losing the tariff revenues. Now, the higher the tariff rate, the smaller are the terms-of-trade benefits. Therefore, in order for country $i$ to be willing to raise its tariff, the increment of the probability with which country $i$ loses the tariff revenues, i.e., $f\left(t_{i}\right)$, should be small when $t_{i}$ is already high.

Next, consider the case in which the two countries are so asymmetric, i.e., $\alpha$ is so small, that the entire region of $t_{1}>t_{2}$ corresponds to either case $\mathrm{C}$ or the case with no trade. Since country 1 is very small and has only a small effect on the market, $\tau_{1}^{A}\left(t_{2}\right)$ is small, as shown in the region of $t_{1}<t_{2}$ in Figure $8 .{ }^{4}$ Since country 2 is very large, on the other hand, its best response $\tilde{\tau}_{2}^{A}\left(t_{1}\right)$ takes a positive value for a small $t_{1}$. Therefore, there exists a pure-strategy Nash equilibrium in which the large country's tariff rate is higher than the small country's, which is depicted as the point $N$ in Figure 8. Thus, we have confirmed Richardson's (1995) conjecture.

Proposition 3 If the two FTA member countries are sufficiently different in the market size, there is a pure-strategy Nash equilibrium in which the larger country chooses a higher tariff rate than the smaller country.

The larger country is "willing" to sacrifice the tariff revenues in order to improve the terms of trade against the ROW.

\footnotetext{
${ }^{4}$ As $\alpha$ approaches zero, the best response curve in this region approaches the vertical axis.
} 


\section{Concluding Remarks}

We have extended Richardson's (1995) tariff competition model into the case of asymmetric FTA member countries. We have confirmed his result when countries are symmetric that (i) there is a unique pure-strategy Nash equilibrium in which both countries completely eliminate their individual external tariffs in the case of inelastic terms of trade with respect to the external tariffs, and (ii) there does not exists a pure-strategy Nash equilibrium in the case of elastic terms of trade. In addition, we have characterized the mixed-strategy equilibrium when countries are symmetric. We have also confirmed his conjecture that the two countries choose positive tariffs when they are sufficiently different in the market size.

While we have focused on the case of FTAs in this paper, it is our future task to compare the result of this paper with that in the case where member countries form a CU. It is also fruitful to extend this analysis to a more general case in which FTA member countries have comparative advantages on different goods, so that they exchange those goods between themselves as well as with the ROW. After all, the exchange of market access is a core idea of PTAs. 


\section{Appendix}

Proof of Lemma 2: Given the argument provided in the main text, we need only show that country $i$ prefers $\tau_{i}^{A}\left(t_{-i}\right)$ to $\tilde{\tau}_{i}^{A}\left(t_{-i}\right)$ in response to $t_{-i} \in\left(\bar{\tau}_{-i}, \infty\right)$.

We first observe from $t_{1}^{B C}>t_{2}^{B C}$ as shown in Figure 6 that whenever country 1 is faced with the choice of whether or not to set a higher tariff rate than its partner's in order to improve the terms of trade, it compares $\tilde{\tau}_{1}^{A}\left(t_{2}\right)$ with $\tau_{1}^{A}\left(t_{2}\right)$ as its best response to $t_{2}$. Whereas country 2 may also be faced with the comparison between $\tilde{\tau}_{2}^{A}\left(t_{1}\right)$ and $\tau_{2}^{C}$

To show that country $i$ prefers $\tau_{i}^{A}\left(t_{-i}\right)$ to $\tilde{\tau}_{i}^{A}\left(t_{-i}\right)$ when both tariff profiles, $\left(\tau_{i}^{A}\left(t_{-i}\right), t_{-i}\right)$ and $\left(\tilde{\tau}_{i}^{A}\left(t_{-i}\right), t_{-i}\right)$ correspond to case $\mathrm{A}$, we first show that $w_{i}^{A}\left(t_{1}, t_{2}\right)>W_{i}^{A}\left(t_{1}, t_{2}\right)$ holds for any $\left(t_{1}, t_{2}\right)$ on $\mathbf{R}_{++}^{2}$. If follows from (5) that when country $i$ selects a lower tariff, social welfare of country $i$ is given by

$$
w_{i}^{A}\left(t_{1}, t_{2}\right)=\int_{p_{W}^{A}\left(t_{1}, t_{2}\right)+t_{i}}^{\infty} D_{i}(p) d p+\int_{0}^{p_{W}^{A}\left(t_{1}, t_{2}\right)+t_{-i}} S_{i}(p) d p+t_{i} D_{i}\left(p_{W}^{A}\left(t_{1}, t_{2}\right)+t_{i}\right) .
$$

Similarly, it follows from (6) that when country $i$ select a higher tariff, its social welfare is given by

$$
\begin{aligned}
W_{i}^{A}\left(t_{1}, t_{2}\right)= & \int_{p_{W}^{A}\left(t_{1}, t_{2}\right)+t_{i}}^{\infty} D_{i}(p) d p+\int_{0}^{p_{W}^{A}\left(t_{1}, t_{2}\right)+t_{i}} S_{i}(p) d p \\
& +t_{i}\left[D_{i}\left(p_{W}^{A}\left(t_{1}, t_{2}\right)+t_{i}\right)-S\left(p_{W}^{A}\left(t_{1}, t_{2}\right)+t_{i}\right)\right] .
\end{aligned}
$$

We extend the domains of $w_{i}^{A}$ and $W_{i}^{A}$ from the set of tariff profiles such that $L\left(t_{1}, t_{2}\right)=$ $i$ and $H\left(t_{1}, t_{2}\right)=i$, respectively, to the entire $\mathbf{R}_{++}^{2}$ in the following analysis.

Now, it follows from (16) and (17) that

$$
w_{i}^{A}\left(t_{1}, t_{2}\right)-W_{i}^{A}\left(t_{1}, t_{2}\right)=\int_{p_{W}^{A}\left(t_{1}, t_{2}\right)+t_{i}}^{p_{W}^{A}\left(t_{1}, t_{2}\right)+t_{-i}} S_{i}(p) d p+t_{i} S\left(p_{W}^{A}\left(t_{1}, t_{2}\right)+t_{i}\right) .
$$

Since the second term on the right-hand side is positive for any positive $t_{i}$, it immediately follows that the sign of (18) is positive if $t_{i}<t_{-i}$. If $t_{i} \geq t_{-i}$, on the other hand, 
the first term on the right-hand side is negative. Since $S_{i}<S$ and the supply function $S$ is upward-sloping, however, we obtain

$$
\begin{aligned}
w_{i}^{A}\left(t_{1}, t_{2}\right)-W_{i}^{A}\left(t_{1}, t_{2}\right) & >t_{i} S\left(p_{W}^{A}\left(t_{1}, t_{2}\right)+t_{i}\right)-\int_{p_{W}^{A}\left(t_{1}, t_{2}\right)+t_{-i}}^{p_{W}^{A}\left(t_{1}, t_{2}\right)+t_{i}} S(p) d p \\
& \geq t_{i} S\left(p_{W}^{A}\left(t_{1}, t_{2}\right)+t_{i}\right)-\left(t_{i}-t_{-i}\right) S\left(p_{W}^{A}\left(t_{1}, t_{2}\right)+t_{i}\right) \\
& =t_{-i} S\left(p_{W}^{A}\left(t_{1}, t_{2}\right)+t_{i}\right) \\
& >0 .
\end{aligned}
$$

That is, (18) is again positive.

Given this observation and the definition of $\tau_{i}^{A}$ being the best response function when $t_{i}<t_{-i}$, we immediately obtain

$$
w_{i}^{A}\left(\tau_{i}^{A}\left(t_{-i}\right), t_{-i}\right) \geq w_{i}^{A}\left(\tilde{\tau}_{i}^{A}\left(t_{-i}\right), t_{-i}\right)>W_{i}^{A}\left(\tilde{\tau}_{i}^{A}\left(t_{-i}\right), t_{-i}\right)
$$

That is, country $i$ prefers $\tau_{i}^{A}\left(t_{-i}\right)$ to $\tilde{\tau}_{i}^{A}\left(t_{-i}\right)$ when both tariff profiles, $\left(\tau_{i}^{A}\left(t_{-i}\right), t_{-i}\right)$ and $\left(\tilde{\tau}_{i}^{A}\left(t_{-i}\right), t_{-i}\right)$ correspond to case A.

Next, we show that $w_{2}^{C}\left(\tau_{2}^{C}\right)>W_{2}^{A}\left(\tilde{\tau}_{2}^{A}\left(t_{1}\right), t_{1}\right)$, i.e., country 2 prefers $\tau_{2}^{C}$ to $\tilde{\tau}_{2}^{A}\left(t_{1}\right)$, when the tariff profile $\left(t_{1}, \tau_{2}^{C}\right)$ corresponds to case $\mathrm{C}$ while $\left(t_{1}, \tilde{\tau}_{2}^{A}\left(t_{1}\right)\right)$ corresponds to case A. Similarly to the above, we first observe $w_{2}^{C}(t)>W_{2}^{A}(t, t)$ for any positive $t$. When $t_{1}=t_{2} \equiv t$, we have $p_{W}^{C}(t)=p_{W}^{A}(t, t)$ and hence the consumer surplus and producer surplus are the same between the two cases even though country 2 plays a role of a low-tariff country in one case and a high-tariff country in the other. However, country 2's import volume is higher in the first case where country 2 is a low-tariff country than in the second case (as $D\left(p_{W}+t\right)-S\left(p_{W}+t\right)$ in the first case whereas $D_{2}\left(p_{W}+t\right)-S\left(p_{W}+t\right)$ in the second case $)$, country 2 earns higher tariff revenues in the first case, so we have $w_{2}^{C}(t)>W_{2}^{A}(t, t)$.

It follows from this observation and the definition of the best response functions 
that

$$
w_{2}^{C}\left(\tau_{2}^{C}\left(t_{1}\right)\right) \geq w_{2}^{C}\left(\tilde{\tau}_{2}^{A}\left(t_{1}\right)\right)>W_{2}^{A}\left(\tilde{\tau}_{2}^{A}\left(t_{1}\right), \tilde{\tau}_{2}^{A}\left(t_{1}\right)\right) \geq W_{2}^{A}\left(\tilde{\tau}_{2}^{A}\left(t_{1}\right), t_{1}\right),
$$

where the last inequality follows from that $\tilde{\tau}_{2}^{A}\left(t_{1}\right) \geq t_{1}$ and that $W_{2}^{A}$ increases in $t_{1}$ due to the terms of trade effect. Thus, we have shown that country 2 prefers $\tau_{2}^{C}$ to $\tilde{\tau}_{2}^{A}\left(t_{1}\right)$.

Proof of Proposition 2: Given the argument provided in the main text, we need only show that $\tau^{m}>0$. Consider the tariff profile near the origin so that the profile corresponds to case A. It follows from (13) and (14) that there exist a positive number $a$ such that the density at a small $t_{i}$ is bounded below by $a / t_{i}$ :

$$
f\left(t_{i}\right)=\frac{\int_{\underline{\tau}^{m}}^{t_{i}} \frac{\partial W_{i}}{\partial t_{i}}\left(t_{i}, t_{-i}\right) f\left(t_{-i}\right) d t_{-i}+\int_{t_{i}}^{\bar{\tau}^{m}} \frac{\partial w_{i}}{\partial t_{i}}\left(t_{i}, t_{-i}\right) f\left(t_{-i}\right) d t_{-i}}{w_{i}\left(t_{i}, t_{i}\right)-W_{i}\left(t_{i}, t_{i}\right)}>\frac{a}{t_{i}} .
$$

Thus, we have

$$
\int_{0}^{\bar{\tau}^{m}} f\left(t_{i}\right) d t_{i}>a \int_{0}^{\bar{\tau}^{m}} \frac{1}{t_{i}} d t_{i}=\infty
$$

which implies that there exists $\underline{\tau}^{m}>0$ such that $\int_{\underline{\tau}^{m}}^{\bar{\tau}^{m}} f\left(t_{i}\right) d t_{i}=1$. 


\section{References}

[1] Cadot, Olivier, Jaime de Melo, and Marcelo Olarreaga. 1999. "Regional Integration and Lobbying for Tariffs against Nonmembers." International Economic Review 40: 635-657.

[2] Furusawa, Taiji and Hideo Konishi. 2004. "Free Trade Networks." COE-RES Discussion Paper Series No. 38, Hitotsubashi University.

[3] Furusawa, Taiji and Hideo Konishi. 2005. "Free Trade Networks with Transfers." Japanese Economic Review 56: 144-164.

[4] Grossman, Gene M. and Elhanan Helpman. 1994. "Protection for Sale." American Economic Review 84: 833-850.

[5] Kemp, Murray C. and Henry Y. Wan, Jr. 1976. "An Elementary Proposition Concerning the Formation of Customs Unions." Journal of International Economics 6: 95-97.

[6] Ohyama, Michihiro. 1972. "Trade and Welfare in General Equilibrium." Keio Economic Studies 9: 37-73.

[7] Panagariya, Arvind and Pravin Krishna. 2002. "On Necessarily Welfare-Enhancing Free Trade Areas." Journal of International Economics 57: 353-367.

[8] Richardson, Martin. 1995. "Tariff Revenue Competition in a Free Trade Area." European Economic Review 39: 1429-1437.

[9] Shibata, Hirofumi. 1967. "The Theory of Economic Unions: A Comparative Analysis of Customs Unions, Free Trade Areas, and Tax Unions." in Carl S. Shoup (ed.). Fiscal Harmonization in Common Markets: Volume I: Theory. 145-264. Columbia University Press. New York. 


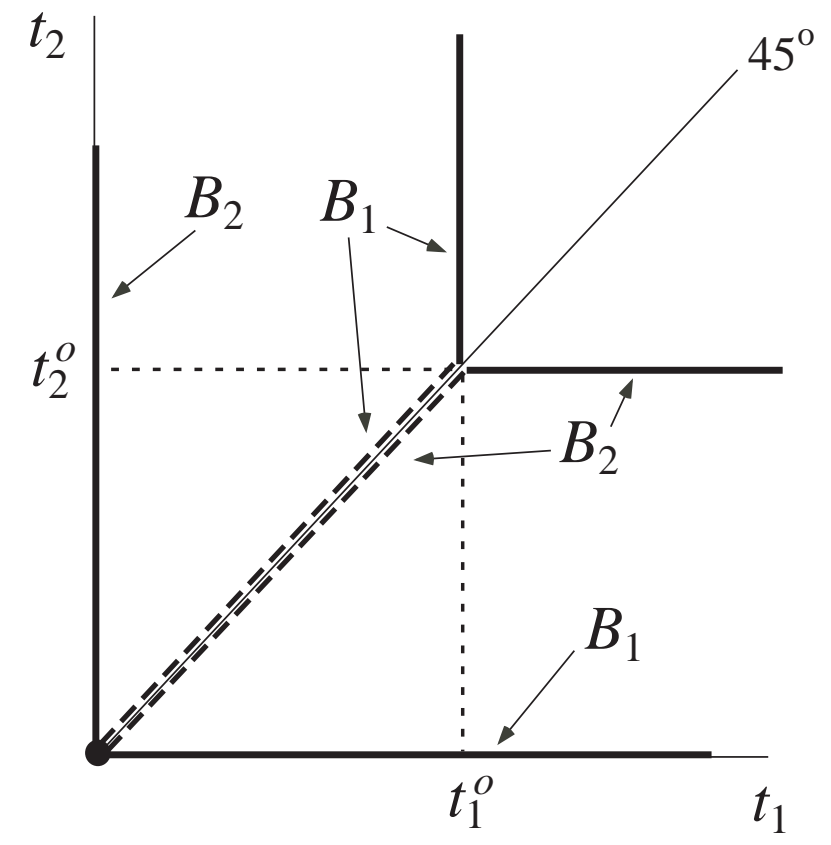

Figure 1: Nash equilibrium in the absence of $\operatorname{ROO}(\alpha=1 / 2)$ 


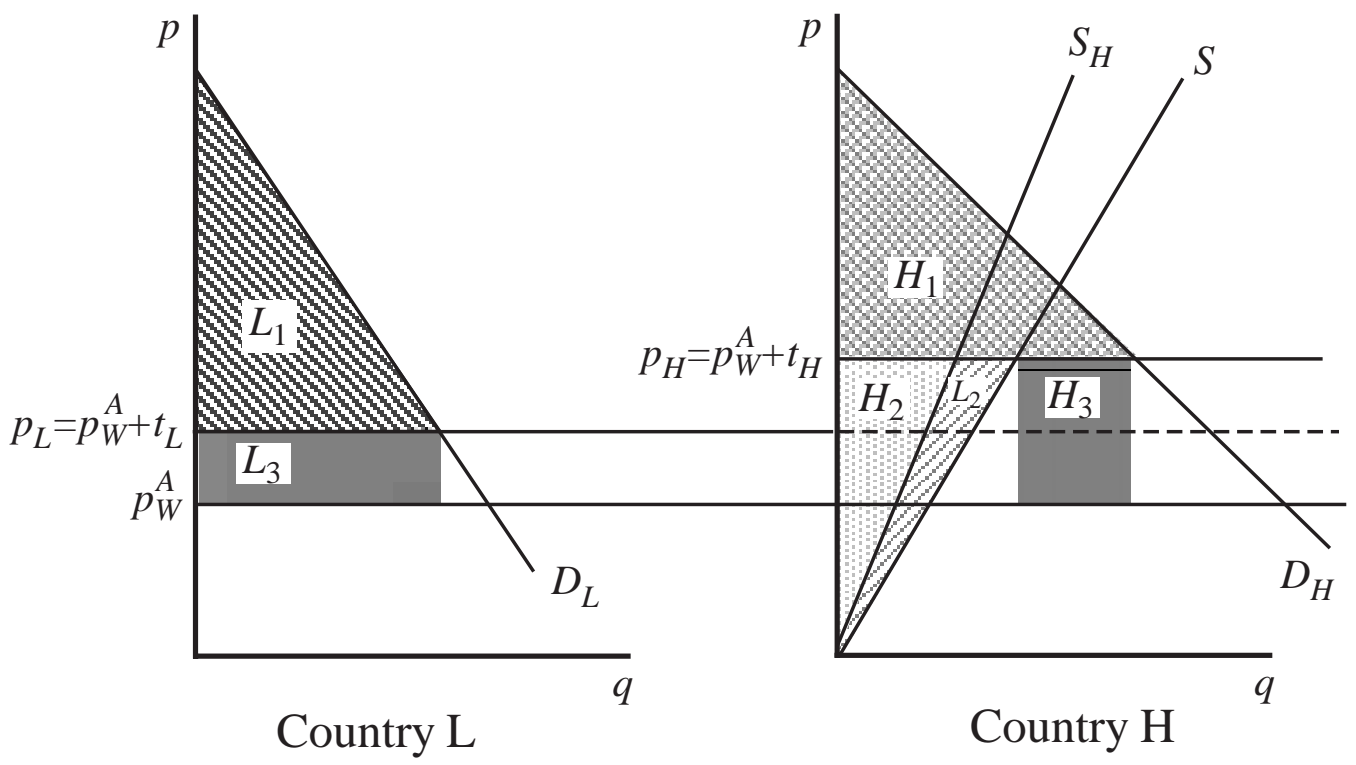

Figure 2: Social welfare: Case A 


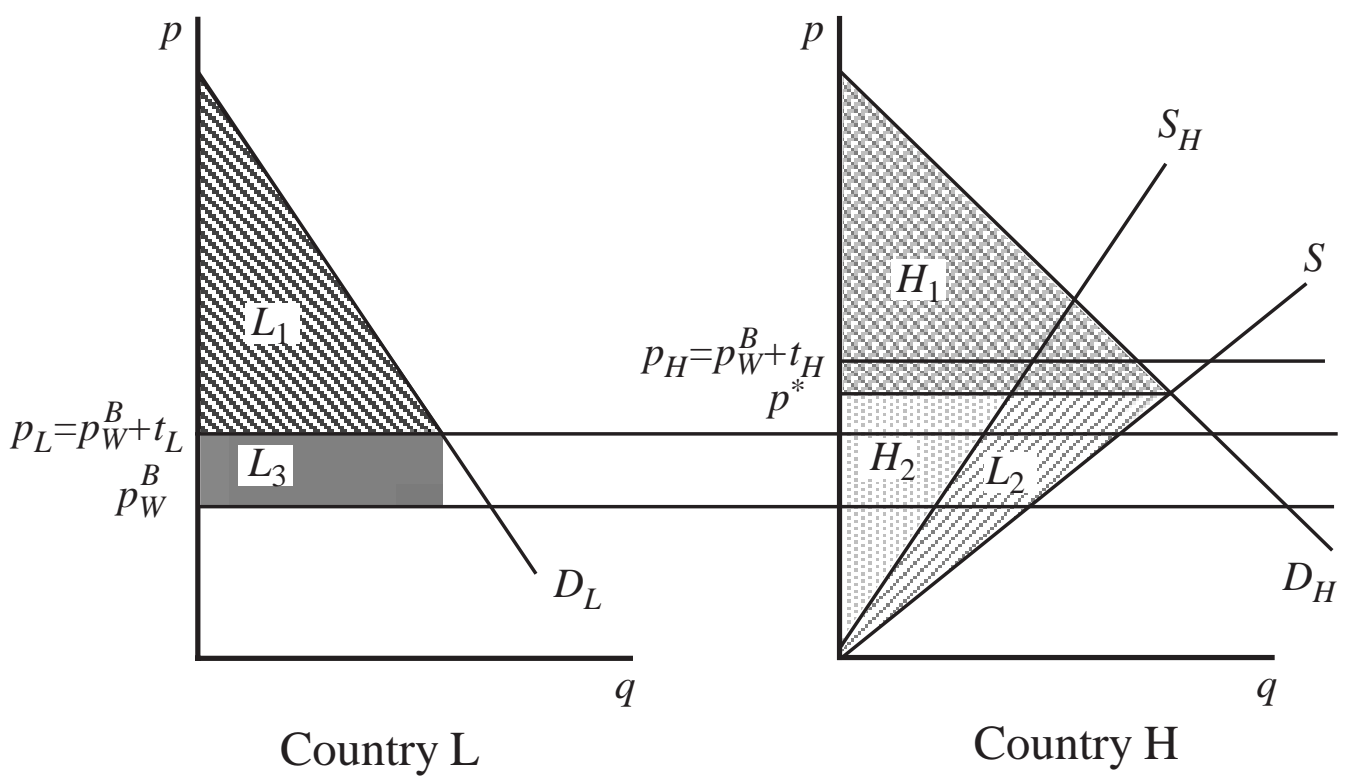

Figure 3: Social welfare: Case B 


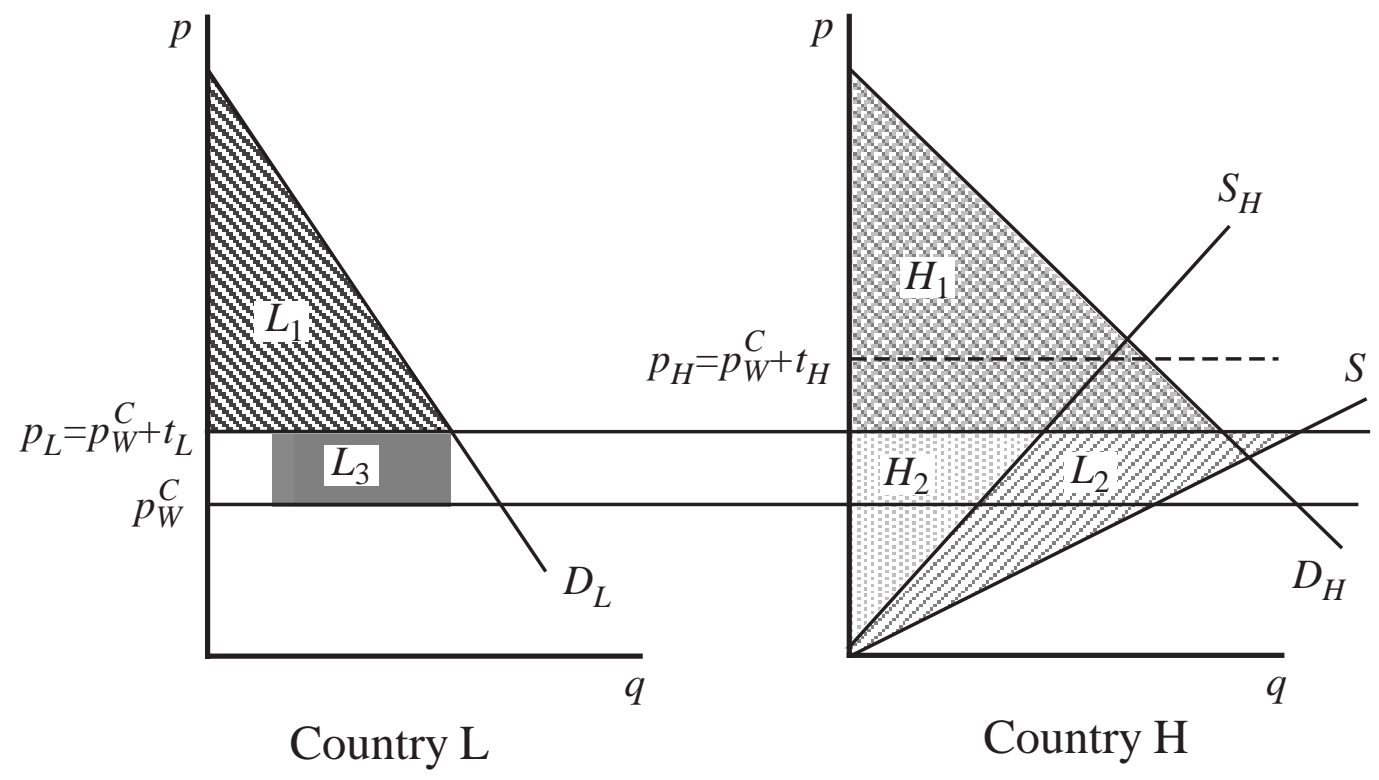

Figure 4: Social welfare: Case C 


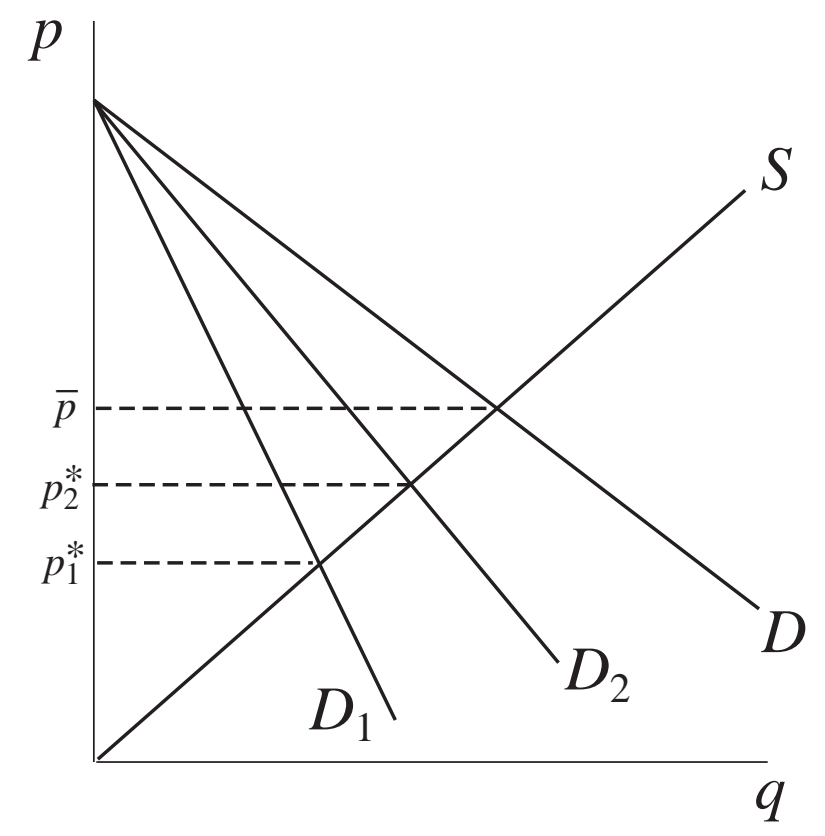

Figure 5: Demand and supply within the FTA 


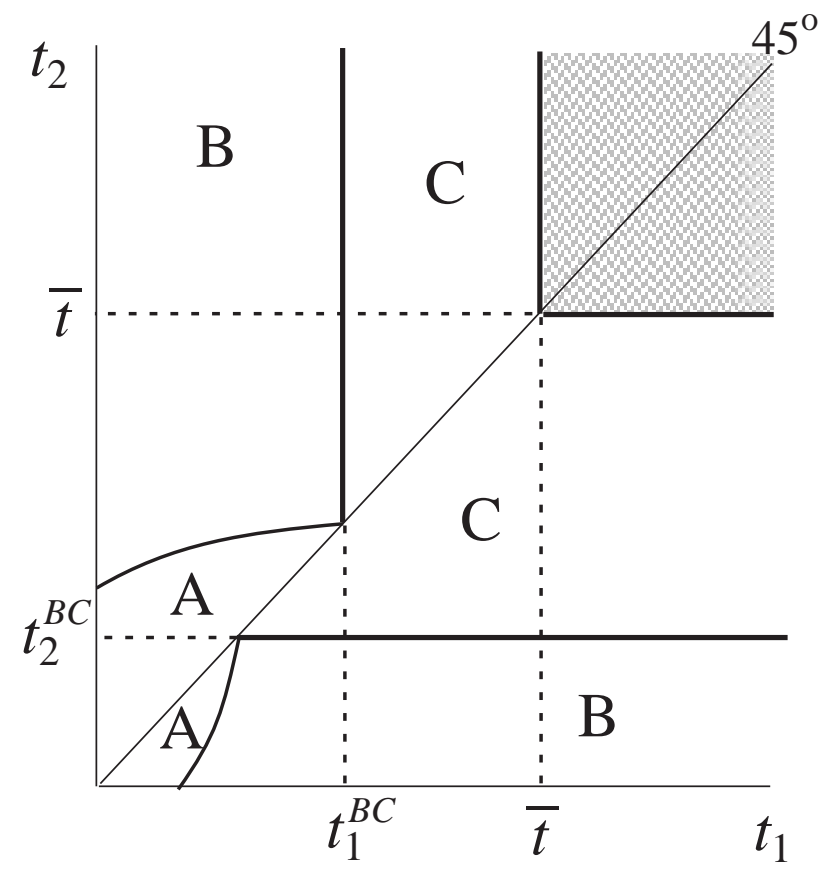

Figure 6: Partition of the tariff plane $(\alpha<1 / 2)$ 


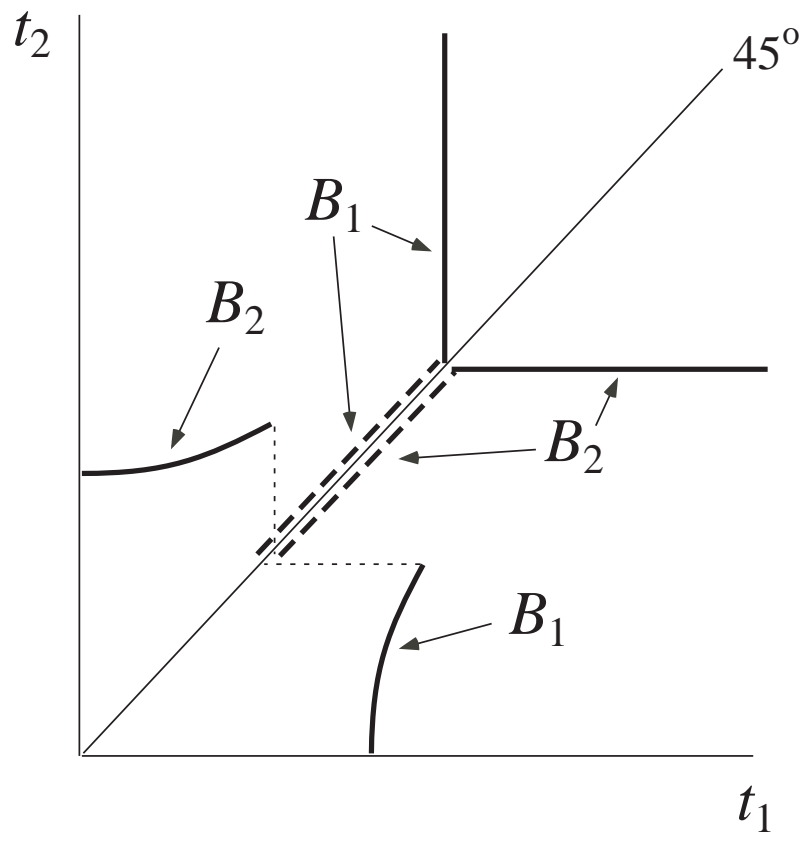

Figure 7: Best responses in the presence of $\operatorname{ROO}(\alpha=1 / 2)$ 


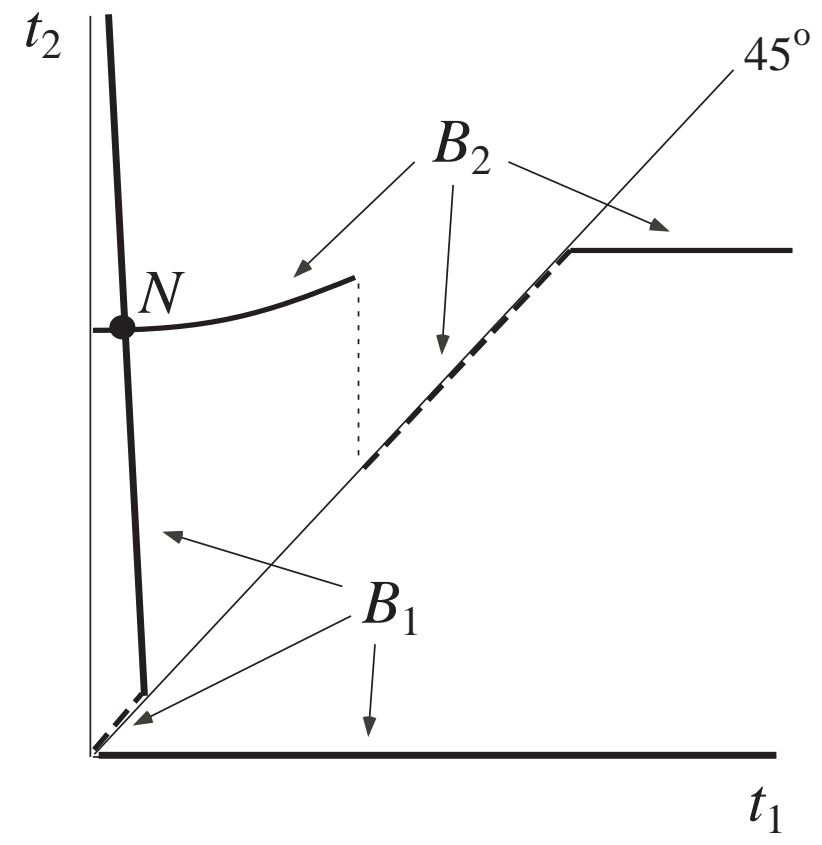

Figure 8: Nash equilibrium in the presence of ROO ( $\alpha$ close to 0 ) 